\title{
The Role of Information Systems in the Effectiveness of Supply Chain Management
}

\author{
Yuyus Yudistria* \\ STIE Ekuitas, The College of Economics, Finance, Banking and Entrepreneurship, Bandung, Indonesia
}

\begin{abstract}
The purpose of this paper is to analyze the conceptual role of Information System (IS) in the effectiveness of Supply Chain Management (SCM). The development of business competition in the field of products or services is increasingly competitive. Competition for product quality is intense in the market. Since products and services are the fastest growing industries in 2018, so it is very necessary to have a good and structured IS that serves to increase the effectiveness of SCM; this will eventually have a positive impact on business performance. At present the IS is needed to increase the effectiveness of SCM. SCM information systems can standardize, monitor, capture and utilize business potential in order to improve business performance. This study adopted a conceptual approach from related theories. To obtain data, interviews of experts/operational management experts (IS \& SCM) were conducted with prompts or probing methods. Moreover, secondary sources such as journals, books and magazines were also used to obtain data. The findings of the study assured the significant role of management IS in achieving effectiveness in SCM. This study concludes that the application of information systems can reduce costs in distribution both from upstream to downstream, can implement good communication and can improve the performance of a company in carrying out SCM.
\end{abstract}

Index Terms - IS, Effectiveness, SCM, Products Quality, Services.

Received: 14 February 2019; Accepted: 27 April 2019; Published: 27 June 2019

\section{Background}

Implementation is needed in order to improve the effectiveness of SCM from a company in general most companies already have a system that is used as an operational guide in shaping the overall integration of company activities. An integrated IS embodies the targets set in the company's development plan.

Besides, the companies is expected to increase their business need to use and develop IS optimally. IS, according to (Whitten \& Bentley, 2007), is a unity of humans, data, processes, and information technology that interact with each other to collect, process, store, and provide output information needed to support an organization. The use of IS today has become a unified procedure for an organization/company because it is believed to be able to support the ongoing business process.

The amount of research in SCM is carried out with various perspectives, one of which is the use of IS in improving supply chain coordination and performance. Research topics such as IS are used to solve problems in the function of supply chains and company performance.

Other research on IS in SCM is proposed as a solution in coordinating supply chain flows and reducing the negative effects of BWE (Sahin \& Robinson, 2002), which are defined as "variations in demand (or orders), starting from the customer to the place of production, demand information passes back through the supply chain" (Chatfield et al., 2004). In other SCM sciences consider the impact of inventory information planning and planning policies on order fulfillment practices (Fan \& Fujimoto, 2018; Gao et al., 2012; Kim et al., 2010). IS prove that these conditions can improve the effectiveness of supply chains and company performance, such as IS relating to raw material suppliers and sharing information with various related fields to enable reduction in inventory costs, thus coordinating together can increase fulfillment of consumer demand.

Recent research related to IS and supply chain performance such as research conducted by Mustafid (2015) which states that supply chain information systems are very important for enhancing various innovations, efficiency and measuring business performance. As well as research conducted by Ojha et al. (2019) states that IS will have an impact on SCM performance.

\section{Literature Review}

$I S$

IS is an information generating system. With the integration between sub-systems, the IS will be able to provide quality, precise, fast, and accurate information in accordance with the management who needs it.

According to Jogiyanto (2005), IS is a system within an organization that brings together the needs of daily transaction processing, supports operations, is managerial and strategic activities of an organization and provides certain outside parties with the necessary reports. Information

\footnotetext{
"Email: yys.yudistria@gmail.com
} 
is generated by an IS process and aims to provide information to assist management decision-making, day-to-day company operations and information that is appropriate for the company. Furthermore, according to Susanto (2000), IS is a blend of humans, technological tools, media, procedures and controls that aim to organize communication networks so that they can assist in making the right decisions.

Activities contained in IS include:

- Input: Describes an activity to provide data to be processed.

- The process: Describes how a data is processed to produce a value-added information.

- Output: An activity to produce a report from the above process.

- Storage: An activity to maintain and store data.

- Control: An activity to ensure that the IS goes as expected.

\section{IS component}

The IS has several components in it. In an IS if one element is not fulfilled, then the IS may not be realized. Integrated IS components function to support and improve the daily operations of the company, also provide information needs for problem solving and management decision making.

According to Kadir (2014) the IS component consists of:

1. Hardware

2. Software or program

3. Procedure

4. People

5. Database

6. Computer networks and data communication.

As according to Susanto (2000) regarding IS components by adding other groupings consisting of:

1. Hardware (Hardware)

2. Software

3. Human

4. Procedure

5. Database

6. Network communication

\section{Supply chain effectiveness}

There are several understandings of SCM found in the literature and according to various professional associations. Some definitions put forward from the three practitioner organizations of SCM are cited in the book "Principles of Supply Chain Management" (Wisner et al., 2012).

The Council of Supply Chan Management Professionals (CSCMP) defines SCM as:

"Planning and management of all activities related to resources and procurement, conversion and all logistics management activities. As a more important part, supply chains include coordination and collaboration with partners such as suppliers, brokers, or third-party services, as well as customers. "

Institute for Supply Chain Management (ISM) defines SCM as:

"Seamless design and management, a process - processes related to the business of providing added value in and between organizational boundaries to find the actual needs of end customers".

The Singapore-based Logistics \& SCM Society, defined SCM as:

"The results of coordination of related techniques to plan and execute all phases in the global network to hold raw materials from providers, transform them into finished goods, and send products and services to customers".

\section{Methodology}

To produce conceptual IS model in the effectiveness of SCM, the following steps are carried out:

1. Identification of grouping and measurement models

2. Reviewing various reference books related to IS and SCM, journals that are by previous and most recent research, previous research reports basic theory in research taken from several sources

3. Opinions of experts and other sources that are deemed accurate and relevant.

Interviews used in research that is using prompts or probing questions, the aim is to explore in exploring and investigating (probes) in research exploration. Respondents in this study were 4 experts / operational management experts (IS and SCM).

\section{Results and Discussion}

The role of IS in the effectiveness of supply chains is to analyze several factors in IS such as:

a. Benefits of information

b. IS Quality

c. IS Success

Method of summarizing the conceptual model of the role of IS is shown as follows:

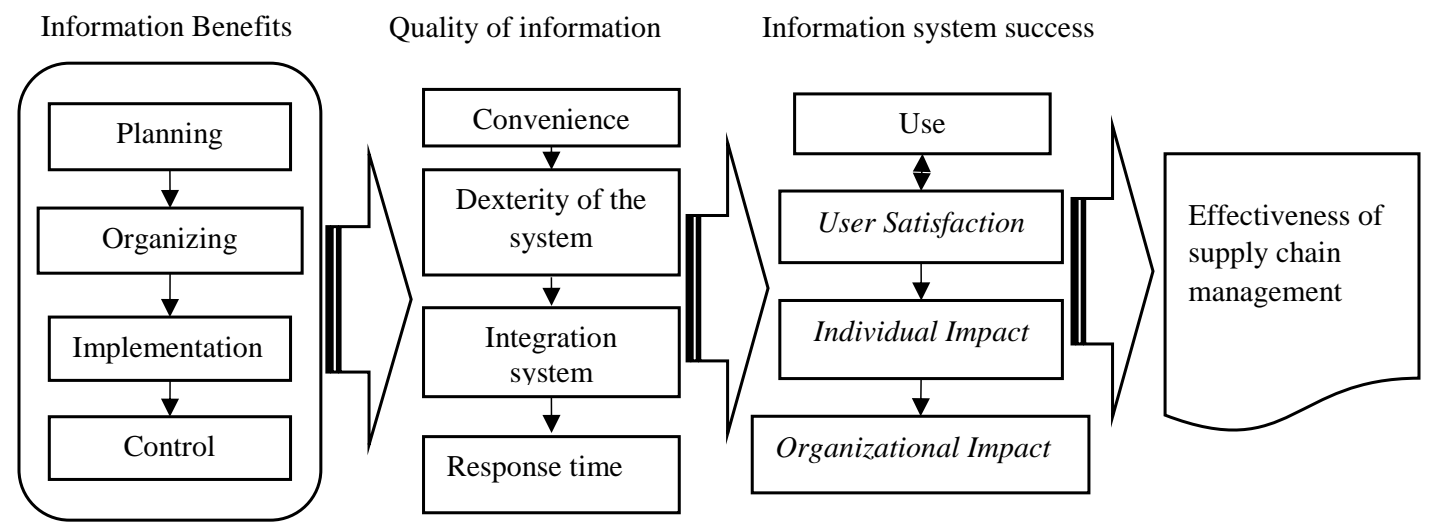

Fig. 1. Conceptual model of the role of IS 
The conceptual model of IS in the effectiveness of the SCM that is designed to build consists of 2, namely grouping models in the IS. The grouping model aims to classify dimensions in IS. Grouping information systems is needed to focus more on the development that will be carried out so that it is feasible to be developed in conjunction with SCM. Grouping information systems can be done by grouping them according to distinguishing characteristics. The distinguishing characteristics are the methods used in relation to the effectiveness of SCM. One grouping in the
IS according to Griffin \& Ebert (2006) is

1. Hardware

2. Software

3. Control

4. Database

5. Brainware (Humans)

6. Telecommunications

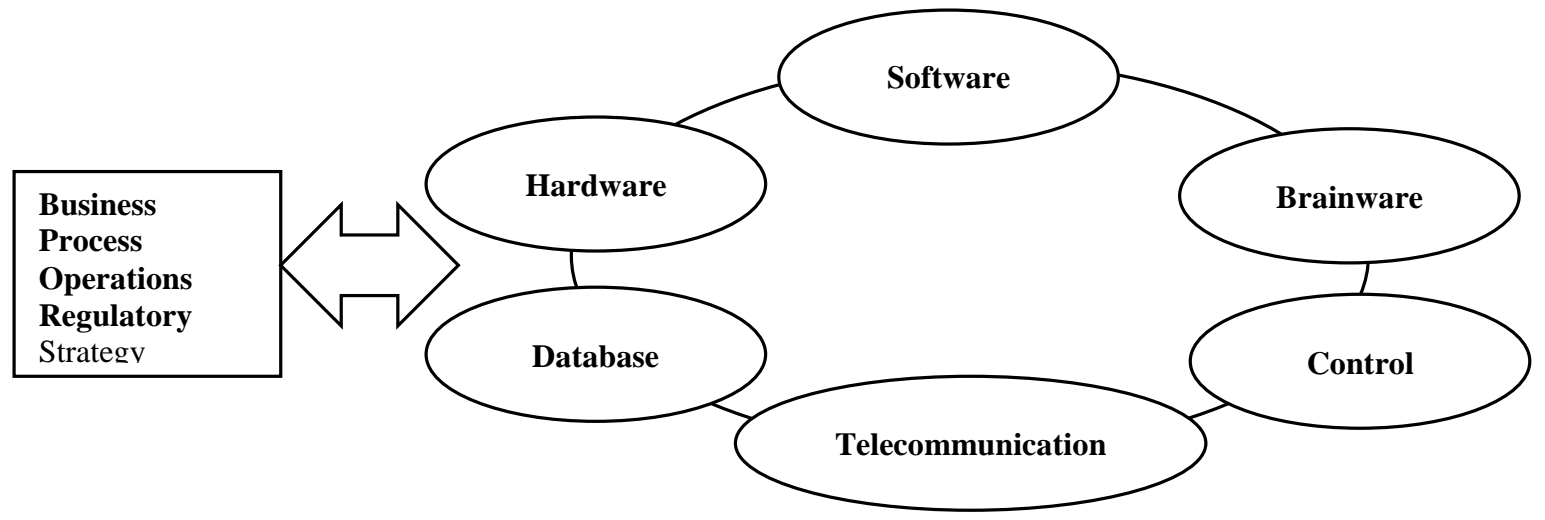

Fig. 2. Unite business strategies with IS Source: Griffin \& Ebert (2006)

The IS model is needed in achieving SCM effectiveness. The approach used refers to Griffin \& Ebert (2006). Therefore, certain strategies will fail if the system components are not integrated to support the system. One strategy in the company is how to reach the level of effectiveness of the supply chain.

In the case of information systems research there are several differences in previous studies in the measurement model as done by 1) Lau \& Lee (2000); 2) Qrunfleh \& Tarafdar (2014); 3) Feng (2012); 4) Mustafid (2015); and 5) Ojha et al. (2019).

Based on the depth of the discussion in the previous study, it did not connect the IS with the level of SCM effectiveness. This causes not to produce an IS relationship in the effectiveness of SCM.

The relationship of IS to the effectiveness of SCM in practice the use of information systems does not cover the entire component such as IS that only involve one operator with one computer but does not involve network and communication facilities, while IS in a company will involve many operators with different fields and multiple computers and need network and communication facilities.

The application of IS in the effectiveness of SCM for the implementation of company activities is very important to get the success of system implementation or failure of the implementation of the system. A lot of research has been done to identify the factors that led to the success of IS. Like research conducted by

1. DeLone \& McLean (1992) developed an IS success model which they called the IS success model.

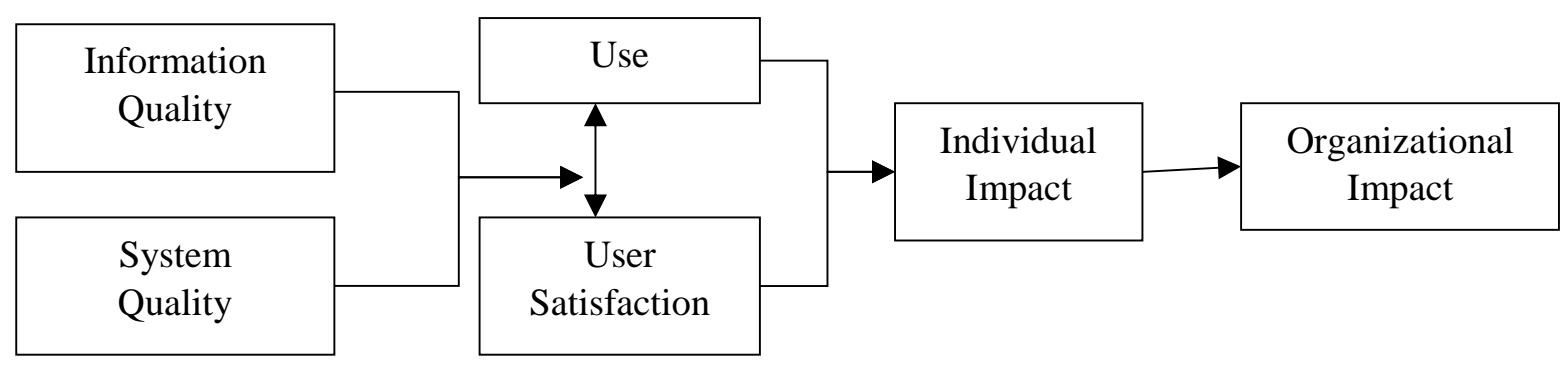

Fig. 3. IS success model

2. Seddon \& Kiew (1996), did not examine up to the measurement of organizational impact, however they developed a model of DeLone \& McLean
(1992), as shown in the figure below. 


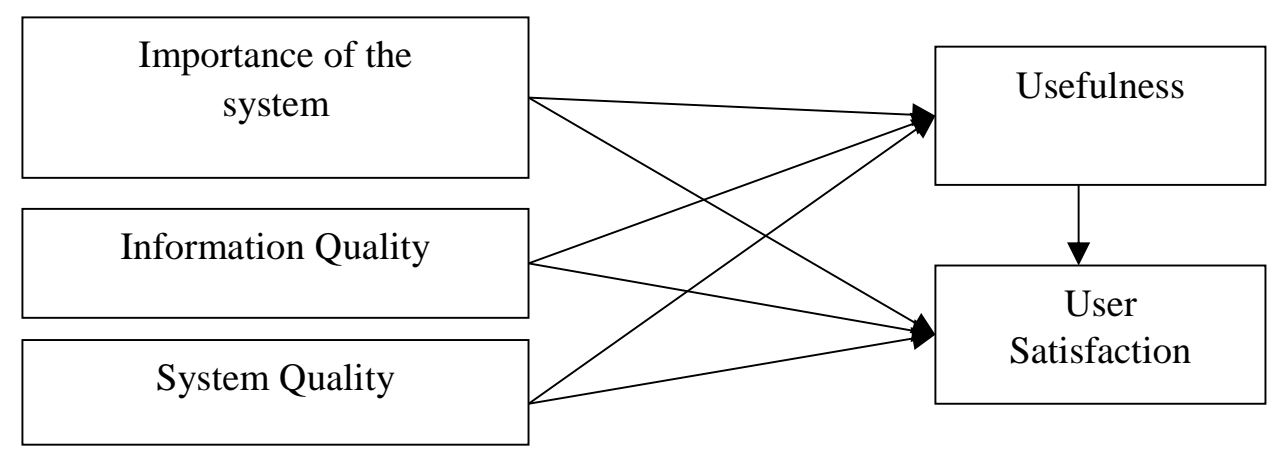

Fig. 4. Model development of DeLone \& McLean (1992)

Most of the successes in management transitions are caused by the accuracy in the use of the IS dimension, even though IS are still underestimated, namely only as data and statistical processing (Ikbar, 2012; Komala, 2017). The use of a fast and precise IS is very significant in implementing supply chain effectiveness as one of the company's competitive strategies. As Donovan \& Williams (2003) states that adopting an IS in the effectiveness of a supply chain requires very large costs, but needs to be considered because the cost of making a mistake due to loss of accurate and fast information or the cost of losing opportunities due to adopting an IS is far greater than the cost needed to build IS.

So that the role of information systems in achieving the effectiveness of SCM needs to apply several criteria as support as in the results of starting an initial activity. Many studies have focused on proving research conducted by several previous researchers in the effectiveness of SCM. While other researchers tried to identify developing strategies from the role of SCM.

When studying the role of IS in achieving the effectiveness of SCM, many researchers have used various approaches including system dynamics methods. Most of the research that has been done on this issue has found that there are various information processes that can improve supply chain capabilities.

Based on the results of interviews with IS and SCM experts, it was found that the role of the IS greatly affects the effectiveness of the implementation of SCM, so that the application of information systems can reduce costs in distribution both from upstream to downstream, can establish good communication and can improve a company's performance in implementing SCM. So thus the role of the IS will have an impact on the effectiveness of implementing SCM.

\section{Limitations and Future Research Directions}

Apart from the theoretical strengths, this study has some limitations. A model for success has been proposed in this study however, this model need to be implemented in various organizations to evaluate its success. Thus, based on the results of the research above, the next research recommendation is the need for research on the implementation of the use of information systems in a company. And in-depth research on the effect of IS implementation in increasing the effectiveness of SCM implementation.

\section{Conclusion}

The role of the IS in the effectiveness of SCM can be done using the stages of analysis, namely the analysis of the benefits of information consisting of planning, organizing, implementing and controlling, then analyzing the quality of information systems consisting of convenience, flexibility, integrated system and response time, so that the next analysis is the suc- cess of the IS consisting of use, user satisfaction, individual impact and organizational impact. Thus, the model designed is interrelated and becomes part of the measurement model input analysis. Thus the designed model of analysis is an integrated model to achieve the objectives of SCM effectiveness.

\section{References}

Chatfield, D. C., Kim, J. G., Harrison, T. P., \& Hayya, J. C. (2004). The bullwhip effect-impact of stochastic lead time, information quality, and information sharing: A simulation study. Production and Operations Management, 13(4), 340-353. doi:https://doi.org/10.1111/j.1937-5956.2004.tb00222.x

DeLone, W. H., \& McLean, E. R. (1992). Information systems success: The quest for the dependent variable. Information Systems Research, 3(1), 60-95. doi:https://doi.org/10.1287/isre.3.1.60

Donovan, J. J., \& Williams, K. J. (2003). Missing the mark: effects of time and causal attributions on goal revision in response to goalperformance discrepancies. Journal of Applied Psychology, 88(3), 379-390. doi:http://dx.doi.org/10.1037/0021-9010.88.3.379

Fan, Z., \& Fujimoto, T. (2018). Construction of knowledge base to visualize the cross-cultural difference over information. Journal of Advanced Research in Social Sciences and Humanities, 3(1), 11-22. doi:https://doi.org/10.26500/jarssh-03-2018-0102

Feng, Y. (2012). System dynamics modeling for supply chain information sharing. Physics Procedia, 25, 1463-1469. doi:https://doi.org/10.1016/j.phpro.2012.03.263

Gao, M., Li, J., \& Zhang, X. (2012). Responses of soil fauna structure and leaf litter decomposition to effective microorganism treatments in Da Hinggan Mountains, China. Chinese Geographical Science, 22(6), 647-658. doi:https://doi.org/10.1007/s11769-012-0573-6

Griffin, R. W., \& Ebert, R. J. (2006). Business (8th ed.). Upper Saddle River, NJ: Prentice Hall.

Ikbar, Y. (2012). Qualitative social research methods. Bandung ,Indonesia: PT. Refika Aditama.

Jogiyanto, H. (2005). Information system analysis and design. Yogyakarta, Indonesia: Andi Publisher.

Kadir, A. (2014). Introduction to the revised edition of information systems. Yogyakarta, Indonesia: ANDI. 
Kim, D.-Y., Kumar, V., \& Kumar, U. (2010). Performance assessment framework for supply chain partnership. Supply Chain Management: An International Journal, 15(3), 187-195. doi:https://doi.org/10.1108/13598541011039947

Komala, A. R. (2017). Cause and effect of accounting information system: A study in national Zakat management organization. Journal of Administrative and Business Studies, 3(2), 69-76. doi:https://doi.org/10.1007/s11769-012-0573-6

Lau, H. C., \& Lee, W. (2000). On a responsive supply chain information system. International Journal of Physical Distribution \& Logistics Management, 30(7), 598-610. doi:https://doi.org/10.1108/09600030010346242

Mustafid, M. (2015). Information systems for knowledge-based sustainable supply chain. Journal of Business Information Systems, 5(2), 109-118. doi:https://doi.org/10.21456/vol5iss2pp109-118

Ojha, D., Sahin, F., Shockley, J., \& Sridharan, S. V. (2019). Is there a performance tradeoff in managing order fulfillment and the bullwhip effect in supply chains? The role of information sharing and information type. International Journal of Production Economics, 208, 529-543. doi:https://doi.org/10.1016/j.ijpe.2018.12.021
Qrunfleh, S., \& Tarafdar, M. (2014). Supply chain information systems strategy: Impacts on supply chain performance and firm performance. International Journal of Production Economics, 147, 340-350. doi:https://doi.org/10.1016/j.ijpe.2012.09.018

Sahin, F., \& Robinson, E. P. (2002). Flow coordination and information sharing in supply chains: Review, implications, and directions for future research. Decision Sciences, 33(4), 505-536. doi:https://doi.org/10.1111/j.1540-5915.2002.tb01654.x

Seddon, P., \& Kiew, M.-Y. (1996). A partial test and development of DeLone and McLean's model of IS success. Australasian Journal of Information Systems, 4(1). doi:https://doi.org/10.3127/ajis.v4i1.379

Susanto, A. (2000). Management information system: Concepts \& development. Bandung, Indonesia: Lingga Jaya.

Whitten, L. J., \& Bentley, D. (2007). System analysis \& design methods. New York, NY: McGraw-Hill.

Wisner, J. D., Tan, K.-C., \& Leong, G. K. (2012). Principles of supply chain management. Toronto, Canada: Nelson Education. 